\title{
Erratum to: Resveratrol in the Prevention and Treatment of Coronary Artery Disease
}

\author{
Louis M. Chu • Antonio D. Lassaletta •
}

Michael P. Robich • Frank W. Sellke

Published online: 21 October 2011

(C) Springer Science+Business Media, LLC 2011

Erratum to: Curr Atheroscler Rep

DOI 10.1007/s11883-011-0202-3

The Disclosure section of the article "Resveratrol in the Prevention and Treatment of Coronary Artery Disease" should read as follows: L.M. Chu: none; A.D. Lassaletta: none; M.P. Robich: supported by 5T32-HL007734; F.W. Selke: consultant for NovoNordisk and Cubist Pharmaceuticals, expert testimony for Pfizer in litigation regarding Celebrex.

The online version of the original article can be found at http://dx. doi.org/10.1007/s11883-011-0202-3.

L. M. Chu • A. D. Lassaletta $\cdot$ F. W. Sellke

Division of Cardiothoracic Surgery, Department of Surgery,

Warren Alpert Medical School of Brown University,

Providence, RI, USA

M. P. Robich

Department of Surgery, Beth Israel Deaconess Medical Center,

Boston, MA, USA

F. W. Sellke $(\bowtie)$

Division of Cardiothoracic Surgery, Alpert Medical School,

Brown University,

593 Eddy Street, APC 424,

Providence, RI 02903, USA

e-mail: fsellke@lifespan.org 